\title{
Campylobacter jejuni e Campylobacter coli EM CARCAÇAS DE FRANGO RESFRIADAS E CONGELADAS
}

\section{Campylobacter jejuni AND Campylobacter coli IN CHILLED AND FROZEN CHICKEN CARCASSES}

\author{
Isabel Cristina Cisco ${ }^{1}$ \\ Denise Tedesco ${ }^{1}$ \\ Gustavo Perdoncini² \\ Suelen Priscila Santos ${ }^{1}$ \\ Laura Beatriz Rodrigues ${ }^{1}$ \\ Luciana Ruschel dos Santos ${ }^{1 *}$ \\ 1 Universidade de Passo Fundo, Passo Fundo, RS, Brasil. \\ ${ }^{2}$ Naturovos, Passo Fundo, RS Brasil. \\ *Autora para correspondência - luruschel@upf.br
}

\section{Resumo}

Espécies de Campylobacter spp. termotolerantes são agentes de surtos de campilobacteriose em humanos e os produtos de origem avícola são considerados uma importante fonte de infecção. Foram identificados Campylobacter jejuni e Campylobacter coli em carcaças de frango resfriadas e congeladas coletadas em três abatedouros entre 2014 e 2015. A detecção de Campylobacter spp. foi realizada por microbiologia convencional e a identificação de $C$. jejuni e $C$. coli por multiplex-PCR. Dentre as amostras avaliadas verificou-se Campylobacter spp. termotolerante em 63,8\%, sendo $72,2 \%$ em carcaças resfriadas e 55,5\% em carcaças congeladas. Destas, 83,3\% foram positivas para C. jejuni e $66,6 \%$ para $C$. coli, enquanto $50 \%$ foram positivas para ambas as espécies. A presença de Campylobacter spp. termotolerante em carcaças de frangos de corte prontas para consumo representa uma importante fonte de transmissão destes patógenos para humanos.

Palavras-chave: abatedouros avícolas; campilobacteriose; termotolerantes.

\begin{abstract}
Species of thermophilic Campylobacter spp. are agents of campylobacteriosis outbreaks in humans, and poultry products are implicated as major sources of infection. The detection of Campylobacter spp. was performed by conventional microbiology in poultry carcasses collected in slaughterhouses and species were identified by multiplex-PCR. Thermophilic Campylobacter spp. was verified in $63.8 \%$ of the samples, being $72.2 \%$ in chilled carcasses and $55.5 \%$ in frozen carcasses. Of these, $83.3 \%$ were positive for $C$. jejuni and $66.6 \%$ to $C$. coli, while $50 \%$ were positive for both. The presence of thermophilic Campylobacter spp. in ready-to-eat poultry products represents a potential source of human campylobacteriosis.
\end{abstract}

Keywords: campylobacteriosis; poultry slaughterhouses; thermophilic bacteria. 
Recebido em: 22 julho de 2016

Aceito em: 26 julho de 2017

\section{Introdução}

A campilobacteriose é uma zoonose emergente de origem alimentar com envolvimento principal de cepas termofílicas Campylobacter jejuni, C. coli, C. lari e C. upsaliensis. Os sintomas clássicos da infecção incluem diarreia, frequentemente hemorrágica, dor abdominal, febre, mialgia e raramente vômito $^{(1,2,3)}$. A doença é reconhecida como um problema de saúde pública e cerca de 76 milhões de ocorrências nos Estados Unidos, com identificação predominante de C. jejuni e C. coli em $\operatorname{surtos}^{(4,5)}$.

Estima-se que entre 50 e $80 \%$ das infecções em humanos teria origem avícola, sendo aves e produtos derivados considerados fontes primárias de campilobacteriose ${ }^{(1,5)}$. Apesar de serem termofílicas em seus requisitos de crescimento, $C$. jejuni e $C$. coli não resistem a altas temperaturas e, consequentemente, não sobrevivem em alimentos pasteurizados ou adequadamente $\operatorname{cozidos}^{(6)}$, além de serem sensíveis à dessecação ${ }^{(7)}$. Entretanto, a superfície das carcaças e miúdos de aves permanecem úmidas durante a comercialização, protegendo as bactérias da dessecação e tornando estes produtos possíveis veículos de Campylobacter spp. ao homem ${ }^{(8)}$.

Existe uma carência de notificações de campilobacteriose e estima-se que a taxa real de infecção seja entre 7,6 a 100 vezes superior à relatada ${ }^{(9)}$. No Brasil não existem programas nacionais de vigilância que investiguem a campilobacteriose a campo ou padrões microbiológicos para alimentos visando Campylobacter spp., possibilitando a ocorrência de surtos de origem alimentar. Neste trabalho são identificadas espécies termotolerantes de Campylobacter spp., associadas a Doenças Transmitidas por Alimentos (DTAs), em carcaças resfriadas e congeladas, prontas para consumo humano.

\section{Material e Métodos}

O trabalho foi realizado entre 2014 e 2015 em três abatedouros de frangos de corte com duas coletas em cada um, amostrando-se carcaças coletadas logo após resfriamento em chiller, resfriadas a $4^{\circ} \mathrm{C}$ por 4 horas e congeladas a $-12{ }^{\circ} \mathrm{C}$ por 24 horas, em triplicata, totalizando 54 carcaças. No laboratório as amostras foram rinsadas com $400 \mathrm{~mL}$ de água peptonada tamponada (APT, Oxoid ${ }^{\circledR}$ ) e homogeneizados por 30 segundos.

A detecção de Campylobacter spp. seguiu a ISO 10272-1 ${ }^{(10)}$, utilizando-se Campylobacter coli ATCC 33559 como controle positivo e Escherichia coli ATCC 25922 e Proteus mirabilis ATCC 35659 como controles negativos. Para o enriquecimento $1 \mathrm{~mL}$ de cada amostra foi inoculado em 9 $\mathrm{mL}$ de caldo Bolton e incubados em microaerofilia (Microaerobac Probac ${ }^{\circledR}$ ) a $37 \pm 1{ }^{\circ} \mathrm{C}$ por 4 horas, sendo posteriormente transferidos para $41,5 \pm 1{ }^{\circ} \mathrm{Cpor} 44 \pm 4 \mathrm{~h}$.

Após, do caldo Bolton inoculou-se $10 \mu \mathrm{L}$ nos ágares Charcoal Cefopezarona Desoxicolato Modificado (mCCDA) (CM739, Oxoid $\left.^{\circledR}, \mathrm{UK}\right)$ e Columbia sangue (CBA) (CM331B, Oxoid $\left.{ }^{\circledR}, \mathrm{UK}\right)$ com suplemento seletivo contendo Cefoperazona 32mg/L e Amfotericina B 10mg/L (SR155, 
Oxoid $\left.{ }^{\circledR}, \mathrm{UK}\right)$, sendo as placas incubadas a $41,5 \pm 1{ }^{\circ} \mathrm{C}$ por $44 \pm 4 \mathrm{~h}$, em microaerofilia. Colônias compatíveis com Campylobacter spp. foram estriadas em Ágar Columbia Sangue (CBA), incubadas a 41,5 $\pm 1{ }^{\circ} \mathrm{C}$ por 24 a 48 horas (microaerofilia) e realizados coloração de Gram, motilidade, oxidase e catalase. Após, as colônias foram armazenadas em Caldo Brucella (CM0169, Oxoid) com glicerol e congeladas $\mathrm{a}-20^{\circ} \mathrm{C}$ até os ensaios de PCR.

A extração de DNA e o multiplex-PCR foram realizadas conforme Borsoi et al. ${ }^{(11)}$. As amostras foram centrifugadas a $12.000 \mathrm{rpm}$ por 10 minutos, o sobrenadante descartado e o pellet obtido suspenso em $800 \mu \mathrm{L}$ de água ultrapura, homogeneizado e centrifugado a $12.000 \mathrm{rpm}$ por cinco minutos. Este procedimento foi realizado quatro vezes e o material ressuspenso em $200 \mu \mathrm{L}$ de água ultrapura. Em seguida, as amostras foram colocadas em bloco térmico entre $96{ }^{\circ} \mathrm{C}$ e $98{ }^{\circ} \mathrm{C}$ por 10 minutos, centrifugadas a $12.000 \mathrm{rpm}$ por 10 minutos e o sobrenadante armazenado para as análises por multiplex-PCR.

Utilizou-se o multiplex-PCR proposto por Denis et al. ${ }^{(12)}$ adaptado por Perdoncini et al. ${ }^{(13)}$ para diferenciar $C$. jejuni e $C$. coli, com três pares de primers para cada reação, baseados na sequência para região 16rRNA comum entre as espécies, como segue: MD16S1 (5'-ATC TAA TGG CTT AAC CAT TAA AC - 3') e MD16S2 (5' -GGA CGG TAA CTA GTT TAG TAT T - 3'), com $857 \mathrm{pb}$. A identificação das espécies $C$. jejuni e $C$. coli foram baseadas no gene mapA e ceuE, respectivamente, com a sequência de primers MDmapA1 (5' -CTA TTT TAT TTT TGA GTG CTT GTG - 3') e MDmapA2 (5'-GCT TTA TTT GCC ATT TGT TTT ATT A - 3') para o gene mapA e COL3 (5' -AAT TGA AAA TTG CTC CAA CTA TG - 3') e MDCOL2 (5' -TGA TTT TAT TAT TTG TAG CAG CG-3') para o gene $c e u \mathrm{E}$.

As reações ocorreram em termociclador (Biocycler-Peltier Thermal Cycler) com desnaturação inicial de $95^{\circ} \mathrm{C}$ por 10 minutos; 35 ciclos a $95{ }^{\circ} \mathrm{C}$ por 30 segundos; anelamento a $59{ }^{\circ} \mathrm{C}$ por 1 minuto e 30 segundos; extensão a $72{ }^{\circ} \mathrm{C}$ por 1 minuto e extensão final a $72{ }^{\circ} \mathrm{C}$ por 10 minutos. A eletroforese dos amplicons foi realizada em gel de agarose a 1,5\% (Invitrogen), corado com brometo de etídio e visualizado por foto documentação com transluminador ultravioleta (UV) (ATTO®).

\section{Resultados e Discussão}

Verificou-se positividade para Campylobacter jejuni e/ou C. coli em 63,8\% das amostras avaliadas.

Tabela 1. Ocorrência de Campylobacter jejuni e/ou C. coli em carcaças de frango resfriadas e congeladas coletadas em abatedouros avícolas

\begin{tabular}{cccc}
\hline Abatedouro & $\begin{array}{c}\text { Carcaças Resfriadas } \\
\mathbf{( \% )}\end{array}$ & $\begin{array}{c}\text { Carcaças Congeladas } \\
\mathbf{( \% )}\end{array}$ & $\begin{array}{c}\text { Total } \\
\mathbf{( \% )}\end{array}$ \\
\hline A & $33,3 \%(18 / 54)$ & $0 \%(0 / 54)$ & $16,66 \%$ \\
B & $100 \%(54 / 54)$ & $66,6 \%(36 / 54)$ & $83,33 \%$ \\
C & $83,3 \%(45 / 54)$ & $100 \%(54 / 54)$ & $91,7 \%$ \\
TOTAL & $72,2 \%(39 / 54)$ & $55,5 \%(30 / 54)$ & $63,8 \%$ \\
\hline
\end{tabular}


A ocorrência de Campylobacter spp. termotolerantes em carcaças resfriadas foi $72 \%$ e $55 \%$ em carcaças congeladas, indicando o risco potencial de infecções em humanos que venham a consumir estas carcaças. Estes resultados são superiores aos citados por Mulinari et al. ${ }^{(14)}$, que identificou Campylobacter spp. em 43,2\% carcaças de frangos e em 7,7\% dos cortes avaliados, sendo que esta alta porcentagem pode ser extrapolada para os demais estabelecimentos da região, que abatem diariamente cerca de 1 milhão de frangos de corte, advertindo sobre a subnotificação da contaminação pelo agente. Dados do $\mathrm{FDA}^{(15)}$ mostram entre 30 e $100 \%$ das aves portadoras da bactéria e 20 a $100 \%$ de contaminação nos produtos do varejo, em consonância com Medeiros et al. $^{(16)}$, que identificaram Campylobacter spp. em 28\% de amostras em abatedouros, $38 \%$ em supermercados e $7 \%$ em feiras livres.

Sabe-se que o habito culinário da população envolve o cozimento de produtos avícolas, supondo-se que esta ação tenha efeito deletério sobre Campylobacter spp. Entretanto, o risco de contaminação cruzada permanece devido a manipulação das carcaças resfriadas e congeladas.

Franco et al. ${ }^{(17)}$ citam que $C$. jejuni sobrevive em ambientes e alimentos refrigerados melhor do que em temperatura ambiente, contrariando as características tradicionais de outras bactérias. Neste sentido, Maziero e Oliveira ${ }^{(18)}$ analisaram carne de frango após a embalagem no frigorífico, 4 dias a $4{ }^{\circ} \mathrm{C}$ e 28 dias a $20{ }^{\circ} \mathrm{C}$ negativos e concluíram que houve diferença significativa em UFC/g de Campylobacter spp. entre amostras frescas e armazenadas sob refrigeração ou congelamento, indicando a sobrevivência da bactéria em carnes resfriadas.

Esta viabilidade de Campylobacter spp. em amostras resfriadas denota um risco extra de contaminação cruzada dada a capacidade da bactéria em resistir à um método tradicional de conservação de alimentos, o que foi demostrado também por Bhaduri e Cottrell ${ }^{(19)}$ ao citar a sobrevivência de $C$. jejuni a $4{ }^{\circ} \mathrm{C}$ e $-20{ }^{\circ} \mathrm{C}$ em carne de frango artificialmente contaminada e irradiada e mostrar que embora a refrigeração tenha reduzido contagens da bactéria após 3 e 7 dias, células viáveis ainda foram detectadas após 14 dias de estocagem.

Já a sobrevivência de Campylobacter spp. em amostras congeladas é relatada por Lee et al. ${ }^{(20)}$ ao citar que Campylobacter spp. pode ser inativado em temperaturas a partir de $15{ }^{\circ} \mathrm{C}$ negativos. Entretanto, para os autores, o congelamento não eliminaria o patógeno em alimentos previamente contaminados, o que foi demonstrado no presente trabalho, onde 55\% das carcaças de frango congeladas conservaram células de Campylobacter spp. viáveis.

A contaminação cruzada devido à manipulação inadequada de alimentos no ambiente doméstico é uma fonte importante de infecção ${ }^{(21)}$. A positividade encontrada nesse estudo e os resultados demonstrados por outros autores, evidenciando a contaminação por Campylobacter spp. nos produtos avícolas é preocupante, visto que a dose infectante para Campylobacter spp. é baixa. Além disto, as espécies identificadas são termotolerantes, e consequentemente passíveis de causar DTAs. Por tratar-se de um produto resfriado e/ou congelado, onde microrganismos deste gênero podem sobreviver às condições de armazenamento, deve-se reforçar a prevenção das infecções por Campylobacter spp. com instruções claras ao consumidor final, bem como a aplicação das Boas Práticas de Fabricação e a indicação de cozimento adequado a estes produtos. 
Também, como a contaminação em produtos finais é reflexo da contaminação por Campylobacter spp. na cadeia avícola e consequentemente nos abatedouros, necessita-se com urgência que a pesquisa e quantificação desta bactéria conste dos programas sanitários federais, bem como da legislação para alimentos prontos para consumo.

\section{Conclusão}

Verificou-se cepas termotolerantes de Campylobacter spp. em 63,8\% das carcaças de frangos congeladas e resfriadas, indicando estes produtos prontos para consumo como fontes potenciais de campilobacteriose em humanos.

\section{Agradecimento}

Ao apoio financeiro da Fundação de Amparo à Pesquisa do Estado do Rio Grande do Sul (FAPERGS, Programa Pesquisador Gaúcho - PqG - Edital FAPERGS no 004/2012) para a compra de meios de cultura, reagentes e kits de PCR.

\section{Referências}

1. Humphrey T, O'Brien S, Madsen M. Campylobacter as zoonotic pathogens: A food production perspective. International Journal of Food Microbiology. 2007; 117: 237-257.

2. Borsoi A, Nascimento VP 2011. In: Campylobacter em produtos avícolas e sua importância na saúde pública. Disponível em: http://pt.engormix.com/MA-avicultura/ administracao/artigos/campylobacterprodutos-avicolas-sua-t777/124-p0.htm. Acesso em: 03 de abril de 2013.

3. CDC. Central for Disease Control and Prevetion. Campylobacter 2014. Disponível em: http://www.cdc.gov/foodsafety/diseases/campylobacter/index.html. Acesso em: 04 de agosto de 2014.

4. Marinou I, Bersimis S, Ioannidis A, Nicolaou C, Mitroussiaziouva A, Legakis JL, Chatzipanagiotou S. Identification and antimicrobial resistance of Campylobacter species isolated from animal sources. Frontiers in Microbiology. 2012; 3: 1-6.

5. EFSA Journal. European Food Safety Authority. Trends summary report on zoonoses, zoonotic agents and food-borne outbreaks 2015. Disponível em: http://www.efsa.europa.eu/en/efsajournal/doc/3991.pdf. Acesso em: 05 de março de 2015.

6. Park SF. The physiology of Campylobacter species and its relevance to their role as foodborne pathogens. International Journal of Food Microbiology. 2002; 74: 177-188.

7. Forsythe SJ. Microbiologia da segurança alimentar. Rio Grande do Sul: Artmed; 2012. p. 208-212.

8. Hobbs BC, Roberts D. Toxinfecções e controle higiênico-sanitário de alimentos. $2^{\mathrm{a}}$ Ed, São Paulo: Varela; 1999. p.123-124.

9. FAO. Food ans Agriculture Organization of the United Nations. Risk Assessment of thermophilic Campylobacter spp. in broiler chickens. Disponível em: http://www.fao.org/docrep/008/y8145e/y8145e07.htm. Acesso em 01 de julho de 2015.

10. ISO 10272-1:2006. Microbiology of food and animal feeding stuffs - Horizontal method for the 
detection and enumeration of Campylobacter spp. Part 1: Detection method. Internacional Standard -ISO. Geneva 20, Switzerland; 2006. p. 1-16.

11. Borsoi A, Santin E, Santos L, Salle C, Moraes H, Nascimento V. Inoculation of newly hatched broiler chicks with two Brazilian isolates of Salmonella Heidelberg strains with different virulence gene profiles, antimicrobial resistance and pulsed field gel electrophoresis patterns to intestinal changes evaluation. Poultry Science. 2009; 88: 750-758.

12. Denis M, Soumet C, Rivoal K, Ermel G, Blivet D, Salvat G, Colin P. Development of m-PCR assay for simultaneous identification of Campylobacter jejuni and C. coli. Lett Appl Microbiol. 1999; 29: 406-410.

13. Perdoncini G, Sierra AYM, Lima LM, Trindade MM, Gomes MJP, Santos LR, Schmidt V, Nascimento VP. Occurrence of Campylobacter jejuni and C. coli on broiler carcasses after chilling in southern Brazil. Pesquisa Veterinária Brasileira. 2015; 35: 349-352.

14. Mulinari EL, Salvatori RU, Majolo C. Enumeração de Campylobacter em carcaças, cortes e miúdos de frango produzidos no Rio Grande do Sul. Caderno Pedagógico. 2014; 11: 91-98.

15. FDA. Food and Drug Administration. Center For food Safety and Aplied Nutrition 2011. Disponível em: http://www.cdc.gov/ mmwr/prevew/mmwthtml/mm5125a2.htm. Acesso em 12 de maio de 2014.

16. Medeiros VM, Bricio SML, Filgueiras ALL, Clementino MBM. Utilização de caldo Bolton no enriquecimento seletivo em comparação ao plaqueamento direto na pesquisa de Campylobacter spp. em carcaças resfriadas de frango. Revista do Instituto Adolfo Lutz. 2012; 71: 456-461.

17. Franco BDGM, Landgraf M. Microbiologia dos Alimentos. São Paulo. Ed. Atheneu; 2004. 182p.

18. Maziero MT, Oliveira TCR. M. Effect of refrigeration and frozen storage on the Campylobacter jejuni recovery from naturally contaminated broiler carcasses. Brazilian Journal of Microbiology. 2010; 41: 501505 .

19. Bhaduri S, Cottrell B. Survival of cold-stressed Campylobacter jejuni on ground chickens and chicken skin during frozen storage. Appl. Envirom. Microbiol. 2004; 70: 7103-7109.

20. Lee A, Smith SC, Coloe PJ. Survival and growth of Campylobacter jejuni after artificial inoculation onto chicken skin as a function of temperature and packaging 60 conditions. Journal of Food Protection. 1998; 61: 1609-1614.

21. Mattick K, Durhman K, Dominigue G, Jorgensen F, Sen M, Schaffner DW, Humphrey T. The survival of foodborne pathogens during domestic washing up and subsequent transfer onto washing-up sponges, kitchen surfaces, and food. International Journal of Food Microbiology. 2003; 85: 213-226. 